\title{
Evapotranspiration mapping for agricultural water management: An overview
}

\author{
R akesh K umar*, Shweta Shambhavi, Raj esh K umar, Yanendra K umar Singh and K isan Singh \\ Rawat $^{1}$
}

Department of Soil Science and Agricultural Chemistry, Bihar Agricultural University, Sabour, Bhagalpur- 801302 (Bihar), INDIA

${ }^{1}$ Division of Agricultural Physics, Indian Agriculture Research Institute, New Delhi-110012, INDIA

"Corresponding author. Email: rbinnu@ gmail.com

Received: M ay 31, 2013; Revised received: August 10, 2013; Accepted:September 15, 2013

\begin{abstract}
Evapotranspiration (ET) is an essential component of the water balance. Any attempt to improve water use efficiency must be based on reliable estimates of ET, which includes water evaporation from land and water surfaces and transpiration by vegetation. ET varies regionally and seasonally according to weather and wind conditions. Remote sensing based agro-meteorological models are presently most suited for estimating crop water use at both field and regional scales. Numerous ET algorithms have been developed to make use of remote sensing data acquired by sensors on airborne and satellite platforms. The use of remote sensing to estimate ET is presently being developed along two approaches: (a) land surface energy balance (EB) method and (b) Reflectance based crop coefficient and reference ET approach. The reported estimation accuracy varied from 67 to $97 \%$ for daily ET and above $94 \%$ for seasonal ET indicating that they have the potential to estimate regional ET accurately. Automated contours are not confined to specific pre-determined geographic areas (as in MLRA), require less time and cost. The spatial and temporal remote sensing data from the existing set of earth observing satellite platforms are not sufficient enough to be used in the estimation of spatially distributed ET for on-farm irrigation management purposes, especially at a field scale level ( 10 to $200 \mathrm{ha})$. However, research opportunities exist to improve the spatial and temporal resolution of ET by developing algorithms to increase the spatial resolution of reflectance and surface temperature data derived from K1VHRR/Landsat/ASTER/MODIS images using same/other-sensor high resolution multi-spectral images.
\end{abstract}

Keywords: Algorithms, Evapotranspiration, Radiometric, Radiation, Remote sensing

\section{INTRODUCTION}

Evapotranspiration (ET) has been long been recognized as the most important process that plays an essential role in determining exchanges of energy and mass between the hydrosphere, atmosphere and biosphere. ET is an essential component of the water balance. Any attempt to improve water use efficiency must be based on reliable estimates of ET, which includes water evaporation from land and water surfaces and transpiration by vegetation. ET varies regionally and seasonally. Understanding these variations in ET is essential for managers responsible for planning and management of water resources. At a field scale, ET can be measured over a homogenous surface using conventional techniques such as Bowen ratio (BR), eddy covariance (EC) and lysimeter systems. However, these systems do not provide spatial trends (or distribution) at the regional scale especially in regions with advective climatic conditions. Remote sensing based agrometeorological models are presently most suited for estimating crop water use at both field and regional scales.
Numerous ET algorithms have been developed to make use of remote sensing data acquired by sensors on airborne and satellite platforms. The use of remote sensing to estimate ET is presently being developed along two approaches: (a) land surface energy balance (EB) method, and (b) Reflectance based crop coefficient (generally denominated Kcr) and reference ET approach where the crop coefficient $(\mathrm{Kc})$ is related to vegetation indices derived from canopy reflectance values.

$L$ and surface energy balance (EB) method: It uses remotely sensed surface reflectance in the visible (VIS) and near-infrared (NIR) portions of the electromagnetic spectrum and surface temperature (radiometric) from an infrared (IR) thermal band. It convert satellite sensed radiances into land surface characteristics such as albedo, leaf area index, vegetation indices, surface emissivity and surface temperature to estimate ET as a "residual" of the land surface energy balance equation: $\mathrm{LE}=\mathrm{Rn}-\mathrm{G}-\mathrm{H}$

Where, $\mathrm{Rn}$ is the net radiation resulting from the budget of short and long wave incoming and emitted radiation respectively, LE is the latent heat flux from ISSN : 0974-9411 (Print), 2231-5209 (Online) All Rights Reserved ๑ Applied and Natural Science Foundation www.ansfoundation.org 


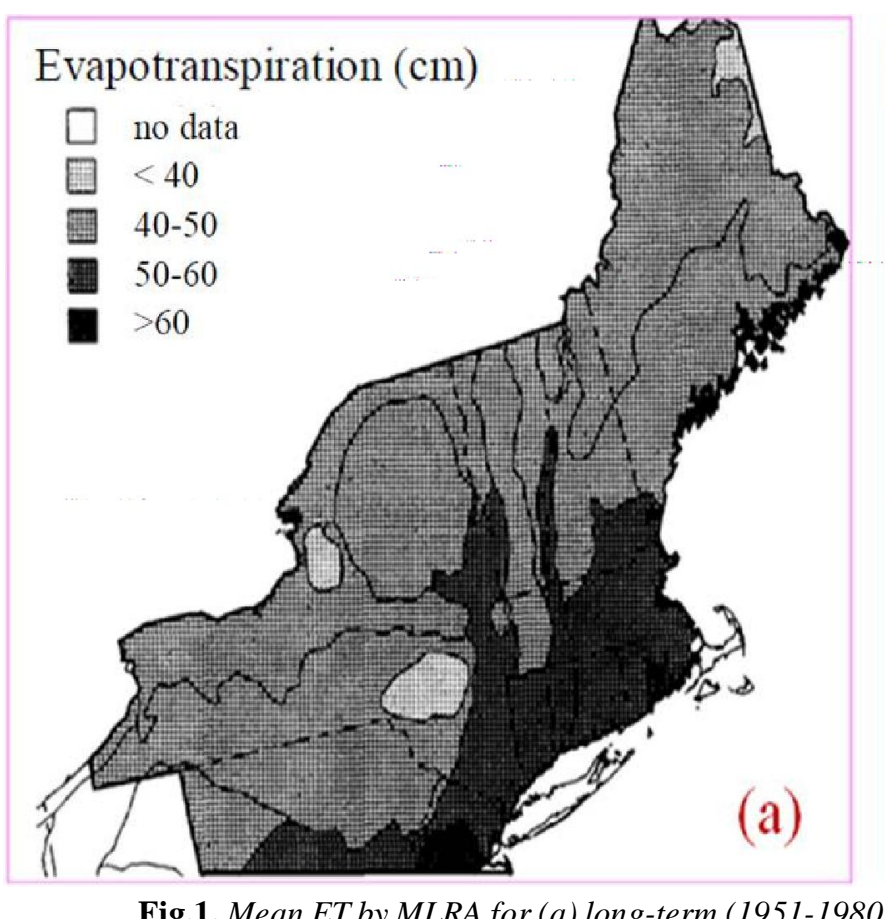

Fig.1. M ean ET by M LRA for (a) long-term (1951-1980) evapotranspiration, $\mathrm{G}$ is the soil heat flux, and $\mathrm{H}$ is the sensible heat flux (all in $\mathrm{W} \mathrm{m}^{-2}$ units). LE is converted to $\mathrm{ET}(\mathrm{mm} / \mathrm{h}$ or $\mathrm{mm} /$ day) by dividing it by the latent heat of vaporization and an appropriate time constant.

Accurate estimates of $\mathrm{H}$ are very difficult to achieve, mainly when Ts is used instead of To and when atmospheric effects and surface emissivity are not considered properly. In such cases, $\mathrm{H}$ prediction errors have been reported to be around $100 \mathrm{~W} \mathrm{~m}^{-2}$ (Cha'vez and Neale 2003). Consequently, more recent EB models differ mainly in the manner that $\mathrm{H}$ is estimated. These models included the two-source model (SEBAL, SEBI),

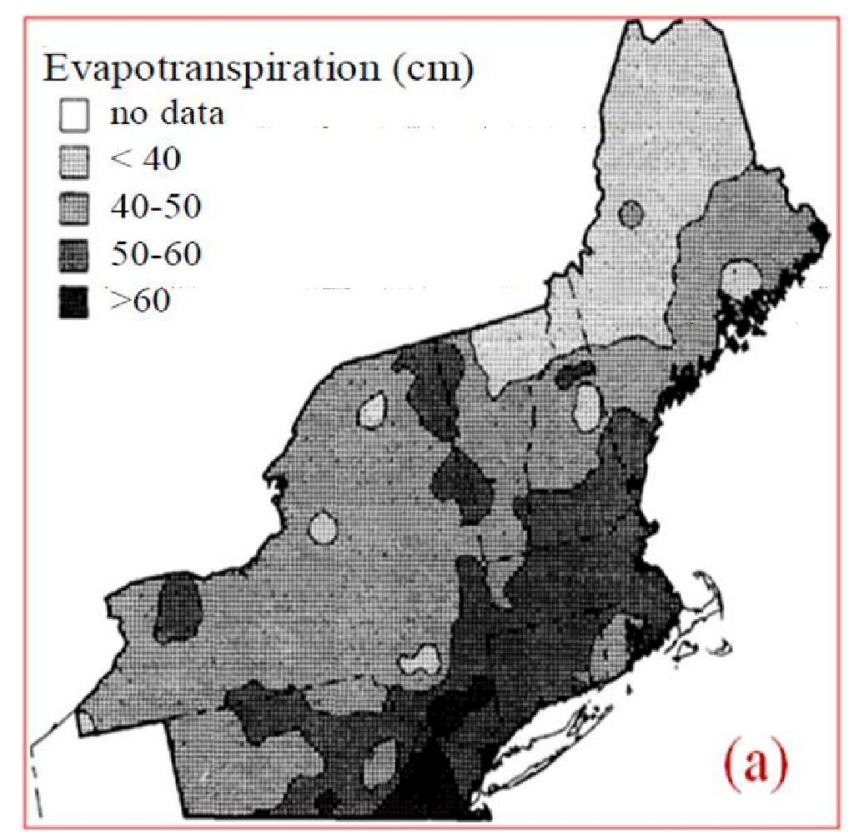

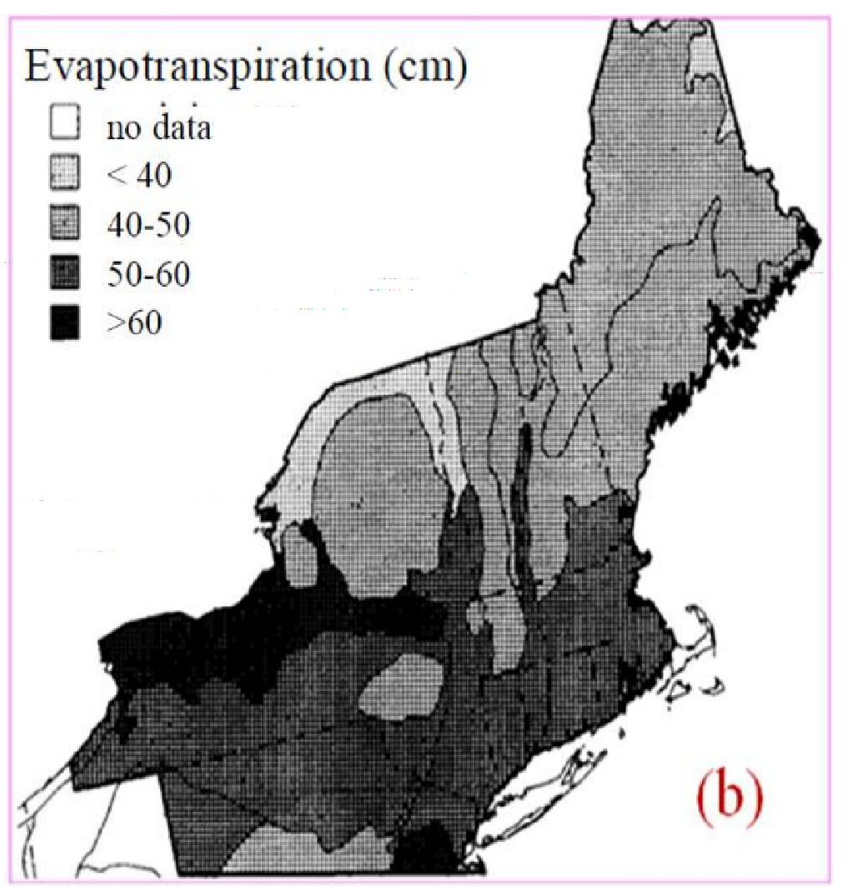

(b) water-year 1984 (Source: Church et al., 1995).

where the energy balances of soil and vegetation are modeled separately and then combined to estimate total LE.

R eflectance based cr op coefficient $(\mathrm{K} \mathrm{cr}$ ) and refer ence ET appr oach: R and NIR reflectance measurements are used to compute a vegetation index (NDVI, SAVI), and the vegetation index is then used in place of calendar days or heat units to drive the crop coefficient. The reference ET is then computed using local meteorological measurements of incoming solar radiation, air temperature, relative humidity or dew temperature, and wind speed. (Rouse et al., 1974).

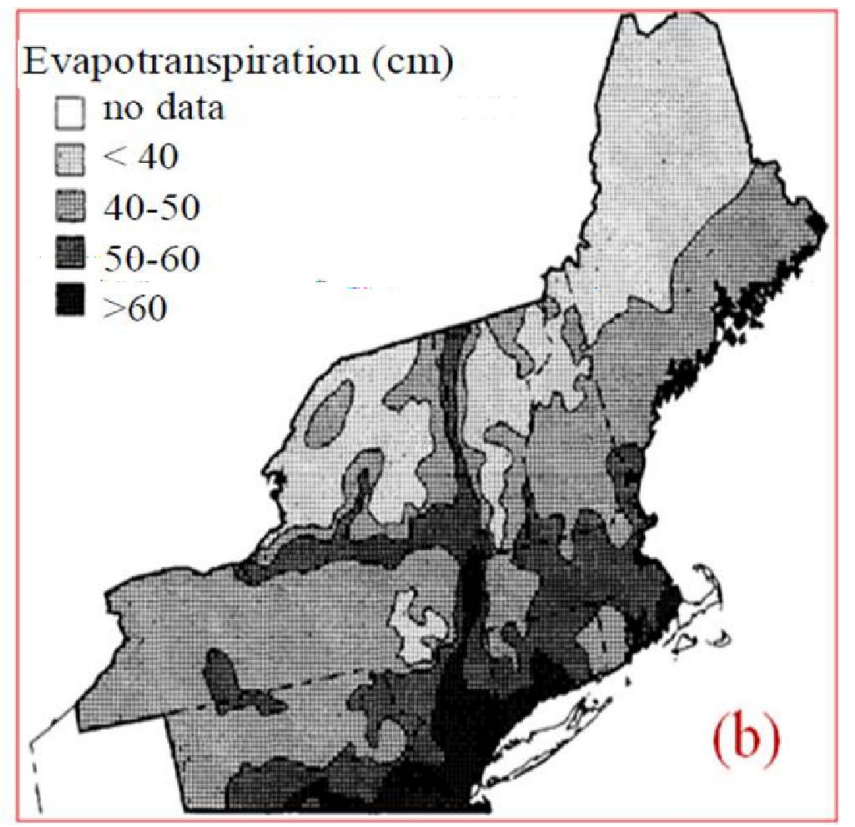

Fig.2. (a) Automatically contoured ET for 1951-1980 (b) M anually contoured ET for 1951-1980 (Source: Church et al., 1995). 

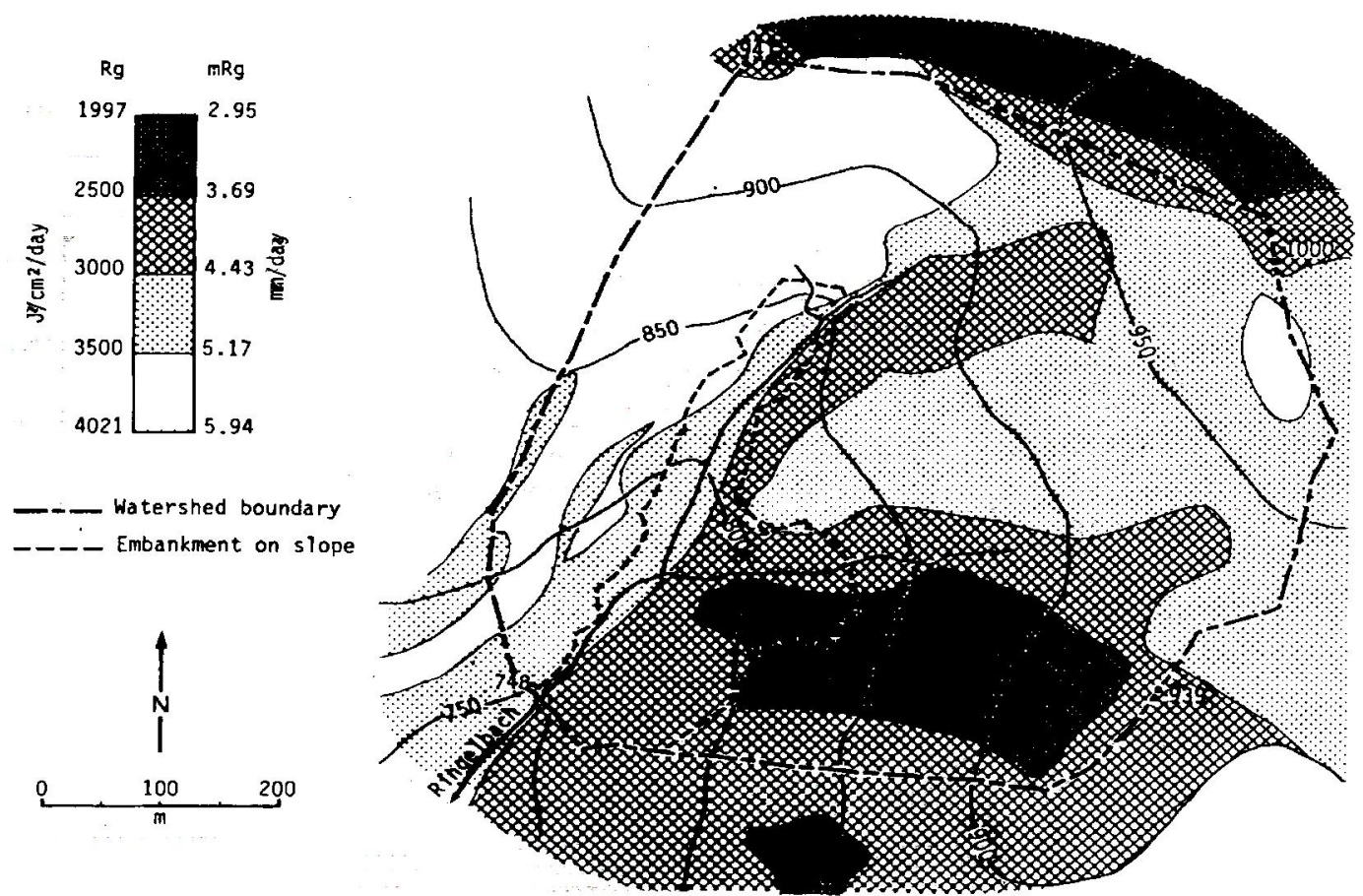

Fig. 3. Map of the global radiation (Rg) (Source: Najjar et al., 1981).

With time advancement, different approaches were adopted by different scientist. Some of the approaches are as follow:

M aps of regional evapotranspiration and runoff/ precipitation ratios in the nor theast United States: Church et al. (1995) compare ET in the NE United States for a long-term period (1951-1980) and for water-year 1984 (WY84). Water-year 1984 is of additional interest because it was a particularly wet year that followed a normal-towet year and thus represents conditions more extreme than long-term normal. They compute ET from the water balance equation and (in one case) modeled estimates of precipitation. We have mapped ET in three different ways. 1. Major land-use resource areas (MLRA)

2. Automated contouring procedure in association with modeled estimates of precipitation from PRISM (Precipitation-elevation regressions on independent slopes model)

3. Manually contoured the variables

MLRA mapping: MLRA were created using physiographic and land use/cover characteristics that have been found to be important to evapotranspiration.

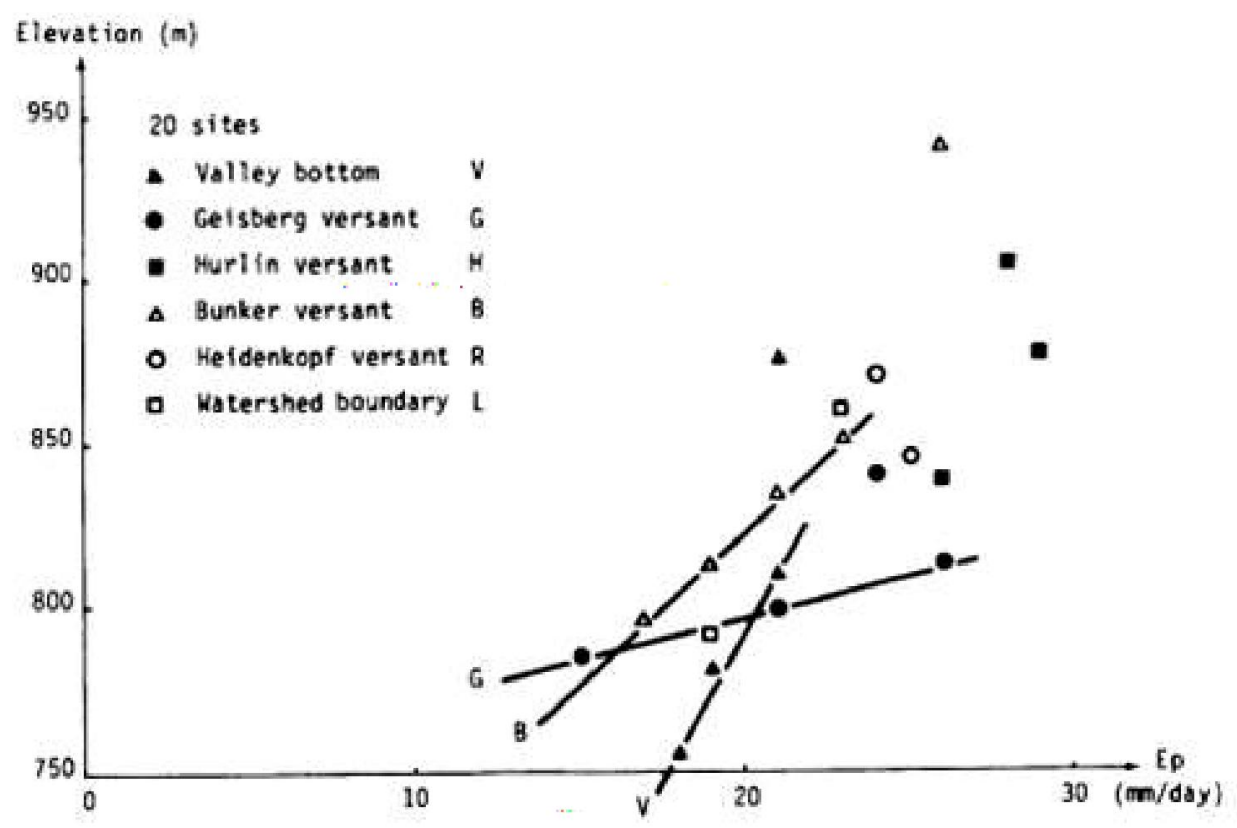

Fig. 4. Daily piche evaporation (Ep) at 20 sites (Source: Najjar et al., 1981). 


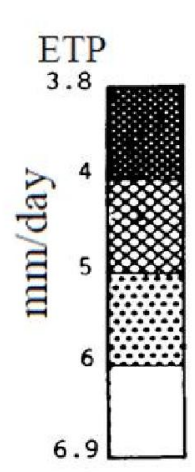

- $\quad$ Piche shelter

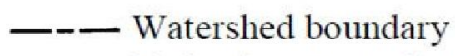

- - - Embankment on slope
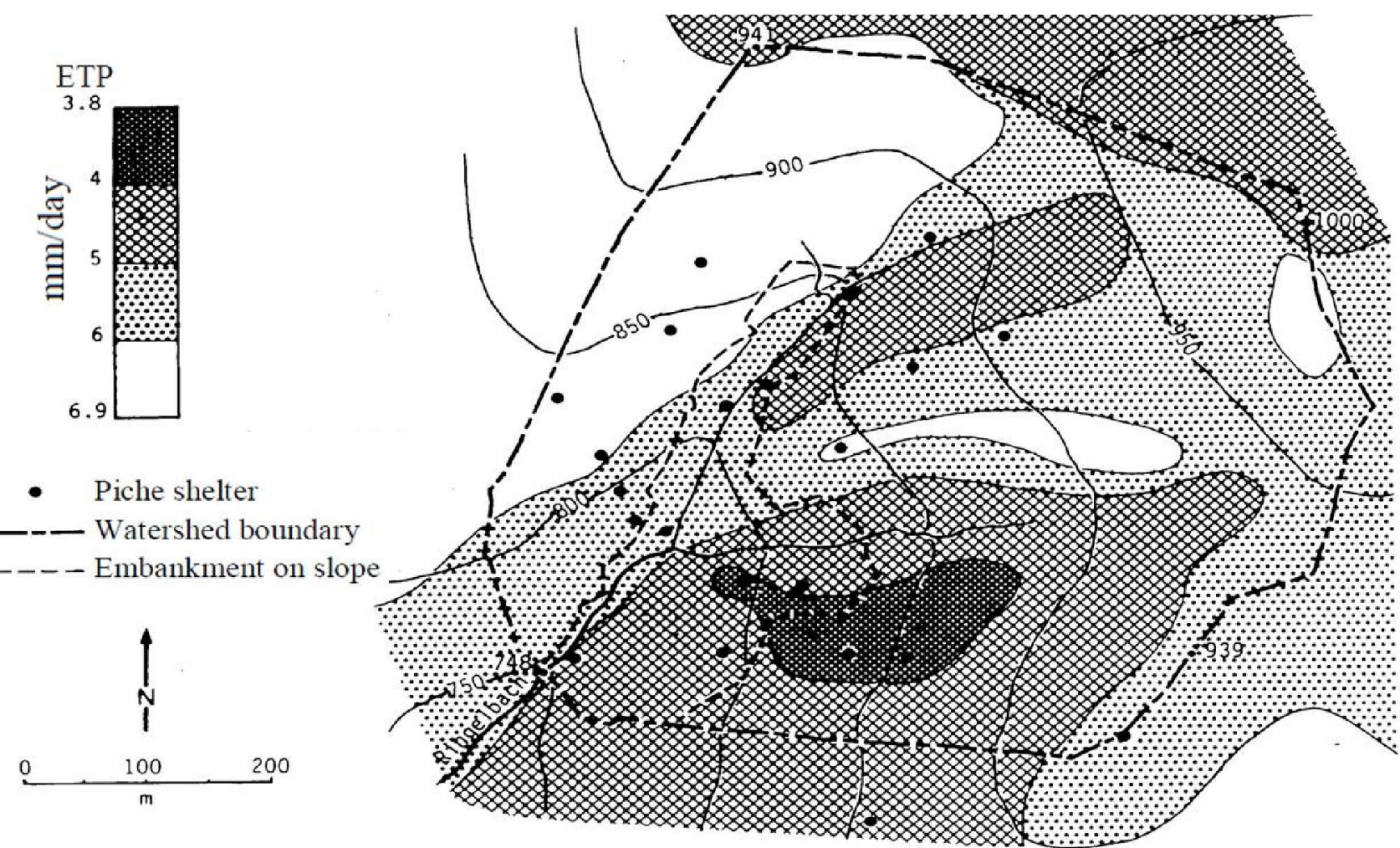

Fig. 5. M ap of ETP according to Brochet and Gerbier's formula (Source: Najjar et al., 1981).
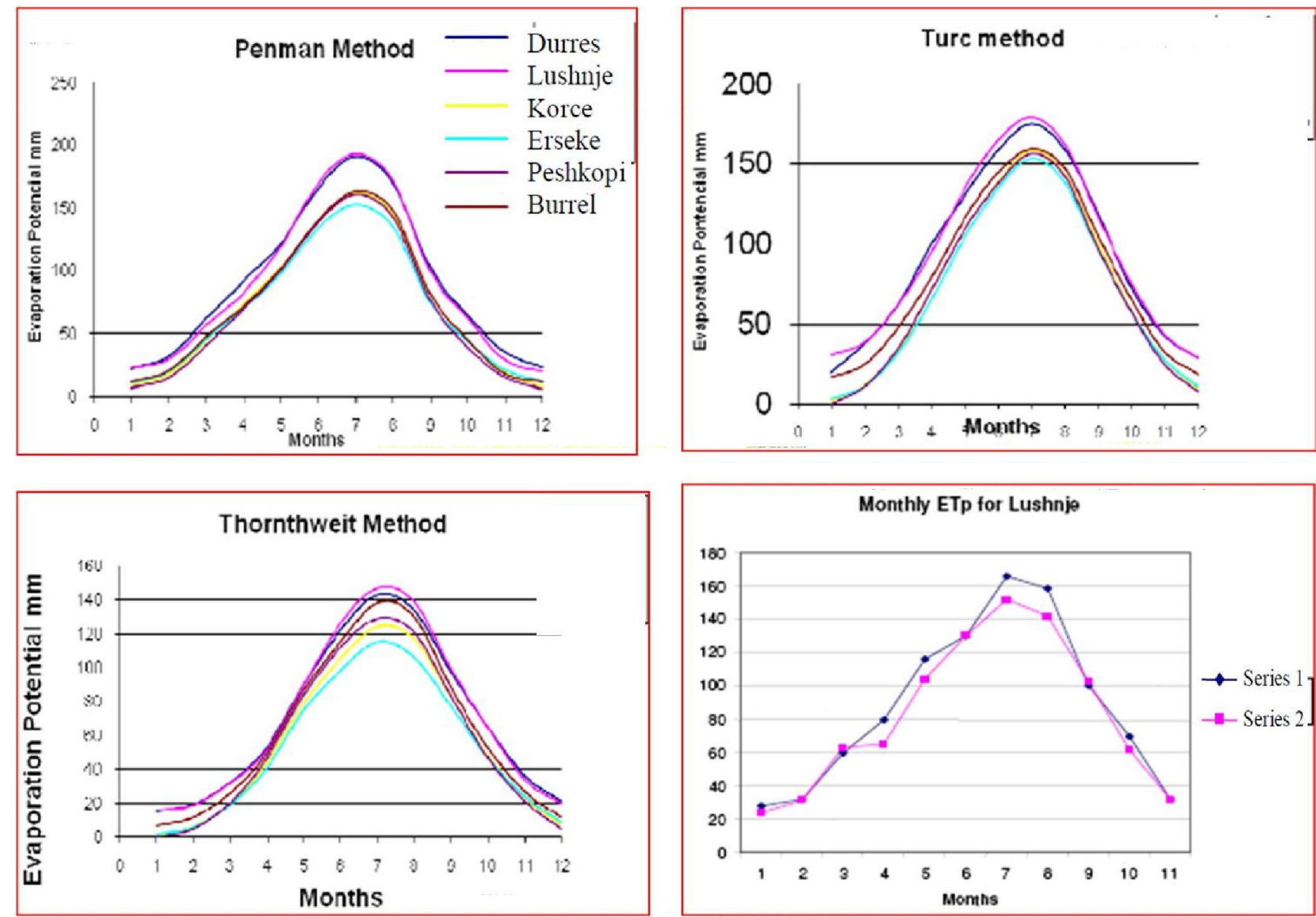

Fig.6. Distribution of monthly E To values (Source: M erkoci etal., 2010). 


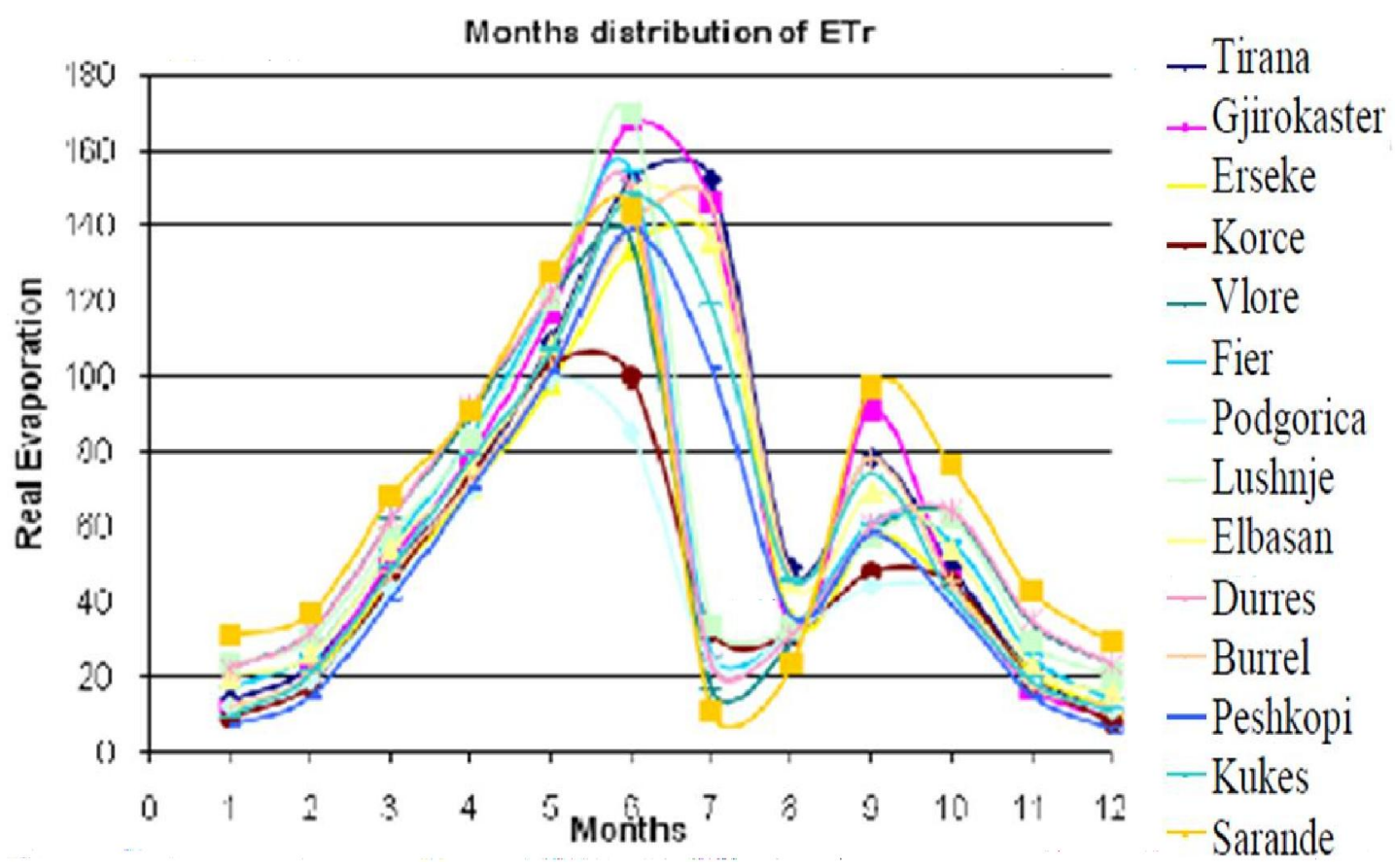

Fig.7. M onthly distribution of $\mathrm{ET}_{\mathrm{R}}$ (Source: M erkoci et al., 2010)

A general pattern of greater ET values in the more southerly regions is evident (Fig.1). This pattern is due directly to the warmer temperatures in those areas indeed; our computed values of ET show a strong linear positive relationship to temperature. In cases where data availability is low, it may be acceptable to rely on the regional boundaries prescribed by MLRA. It allows freedom to exercise informed interpretation that leads usually to a more 'satisfying' (from the point of view of a mapper) spatial representation of patterns in the source data.

Automated and manual contour mapping: Church et al. (1995) produced contour maps generated using automated computational procedures. For our automated contour mapping approach, we used precipitation estimates from the model PRISM. PRISM specifically developed for the purpose of estimating precipitation in areas of significant orographic influence by subdividing mountainous landscapes into a mosaic of individual topographic facets. It uses a digital elevation model (DEM) and develops regression equations. Calculated ET and interpolated the values across the grid using an inverse distance-weighting algorithm and lastly created the contour maps by linear interpolation.

They first plotted the estimated ET values (determined as for the MLRA mapping) at their corresponding sites on a base map and then overlaid this map on an elevation contour map and drew ET contours using elevation

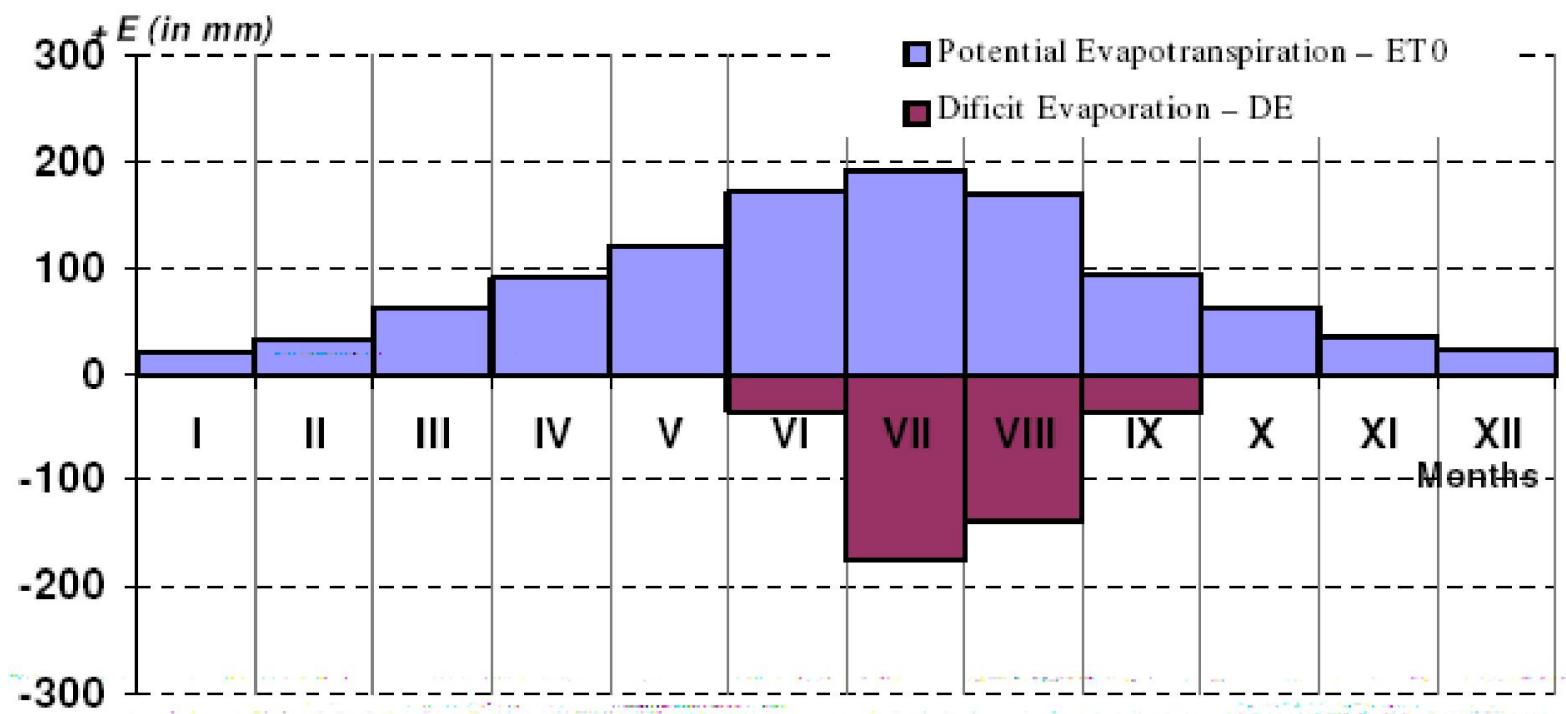

Fig.8. Annual distribution of deficit evaporation ("E) (Source: Merkoci et al., 2010) 


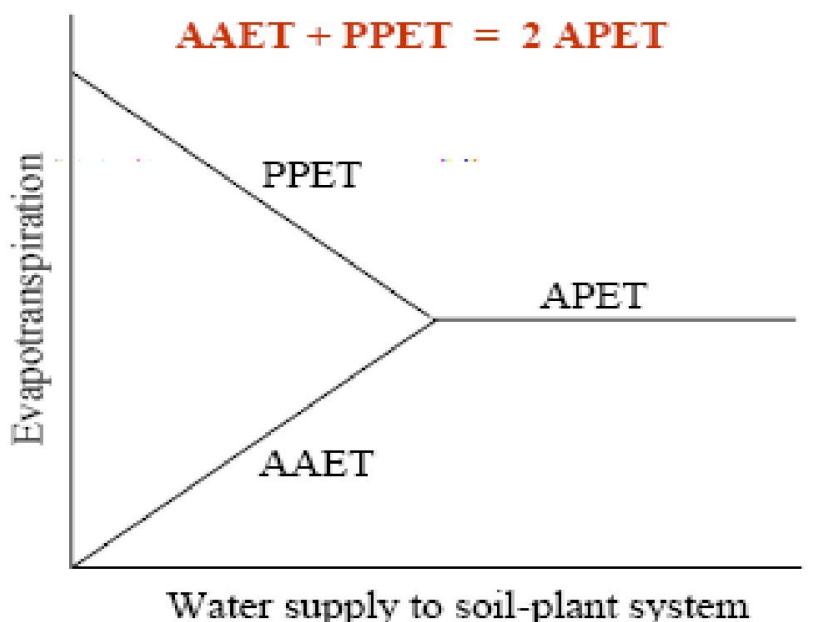

Fig. 9. Complementary relationship between AAET and P PET

(assuming ET decreases with elevation). We then digitized the contours and entered them into a geographic information system (GIS) from which we produced the final maps.

In all cases, less ET in the cooler and more mountainous regions is clearly apparent (Fig.2). It is also apparent that the greater degree of spatial detail is incorporated into our contoured maps, especially the manually contoured maps. When enough data are available to allow relatively accurate contouring, this approach may be preferable.

Automated contouring have several advantages-

Contours are not confined to specific predetermined geographic areas (e.g. MLRA in our case).

Require substantially less time and cost than manual contouring

Disadvantages of manual mapping

It may be biased (i.e. the mapper has an incorrect model).

2. It requires relatively more time and subjective expertise. $M$ easurement and mapping of potential evapotr anspiration in a small mountainous watershed: Najjar et al. (1981) estimated potential evapotranspiration (ETP) by using Brochet and Gerbier's formula (1972)

$\mathrm{ETP}=\mathrm{mRg}+\mathrm{nEp}$

Where $\mathrm{m}$ and $\mathrm{n}$ are tabulated coefficients depending on season, latitude and shelter type, and where the variables are the global solar radiation Rg and the Piche evaporation under shelter Ep. By mapping Rg and Ep, calculate Daily ETP.

In the small Ringelbach watershed (36 ha), in the Vosges Mountains (France), gives a good estimation of ETP, enables us to understand better the hydrologic behaviour of any mountainous watershed.

The global radiation computed for July 2, 1981, a sunny anticyclonic day has been shown in Fig. 3. This map reflects well the main topographic features of the watershed. A maximum radiation arrives on S or SSE versant with heavy slope, minimum on WNW versant. The bottom of the small valley stands out between the two well-contrasted versants. The gobal radiation can double in size from one point to another within the watershed: the extreme values are 1,997 and $4,021 \mathrm{~J} / \mathrm{cm}^{2} /$ day.

Piche evaporometers were implanted at 20 sites in the Ringelbach watershed chosen along some transects, which are representative of the main topographic features of the watershed. Daily Piche evaporation (Ep) measured on July 2, 1981, in these 20 sites has been represented in Fig. 4. It reflects well the topoclimatic structure of the watershed. The evident increase of Ep with increasing altitude reveals in fact how strong is the influence of the air humidity and wind patterns on the Piche evaporation: Ep increases if wind (w) increases and humidity (h) decreases. The Ep variations are linear along each versant, but variation rates depend on the orientation of the versants.

The ETP map determined for July 2, 1981 (Fig. 5), which is rather similar to the Rg map: the radiative term is indeed always much more important than the advective one. Maximal ETP is found on the Geisberg versant which has a high Rg (facing S and SSE) and a high Ep (dry slope). The wet valley (low Ep) has an intermediate ETP because of an intermediate Rg. Moreover, the relative contribution of advective processes to ETP appears to be very variable into the watershed.

This mapping procedure, which is physically based and easy to apply, provides us a good tool for estimating ETP at different scales of space and time from a few point measurements.

M apping evapotranspiration by meteor ological element in the territory of A lbania (South east E urope): Albania is a complicated and complex natural area in Europe as a result of its specific physical-geographical conditions: a mountainous region, typical Mediterranean climate, a particular hydrographical system, etc. Merkoci et al. (2010) classified Albanian territory into three areas: (I)Field areas (II)-Hilly areas (III)-Mountainous areas. Potential Evapotranspiration (reference evapotranspiration) ETp, Real Evapotranspiration - $\mathrm{ET}_{\mathrm{R}}$, Evaporation Deficit $-\Delta E$. Reference (Potential) Evaporation - ET0 is calculated by various methods such as: Turc, Penman, Thornthweit, Penman Monteith, Equation FAO56 Penman-Monteith. The values of ETo, calculated by different ways, result similar to be each-other (Fig.6). These values are relatively similar, to the results of the direct experimental observed method (the Lushnja stations), the difference about $-\Delta$ ETo $= \pm 5 \div 10 \%$. Therefore, the average monthly Reference Evapotranspiration differs from about ET0 $=10$ to $40 \mathrm{~mm}$ in January, the coldest month of the year, to about ET0 = 120 to $170 \mathrm{~mm}$ in June, the hottest month, referring to FAO56 Pennman-Monteith and ASCE Penman Monteith. Real Evapotranspiration $\left(\mathrm{ET}_{\mathrm{R}}\right)$ is by different methods, 


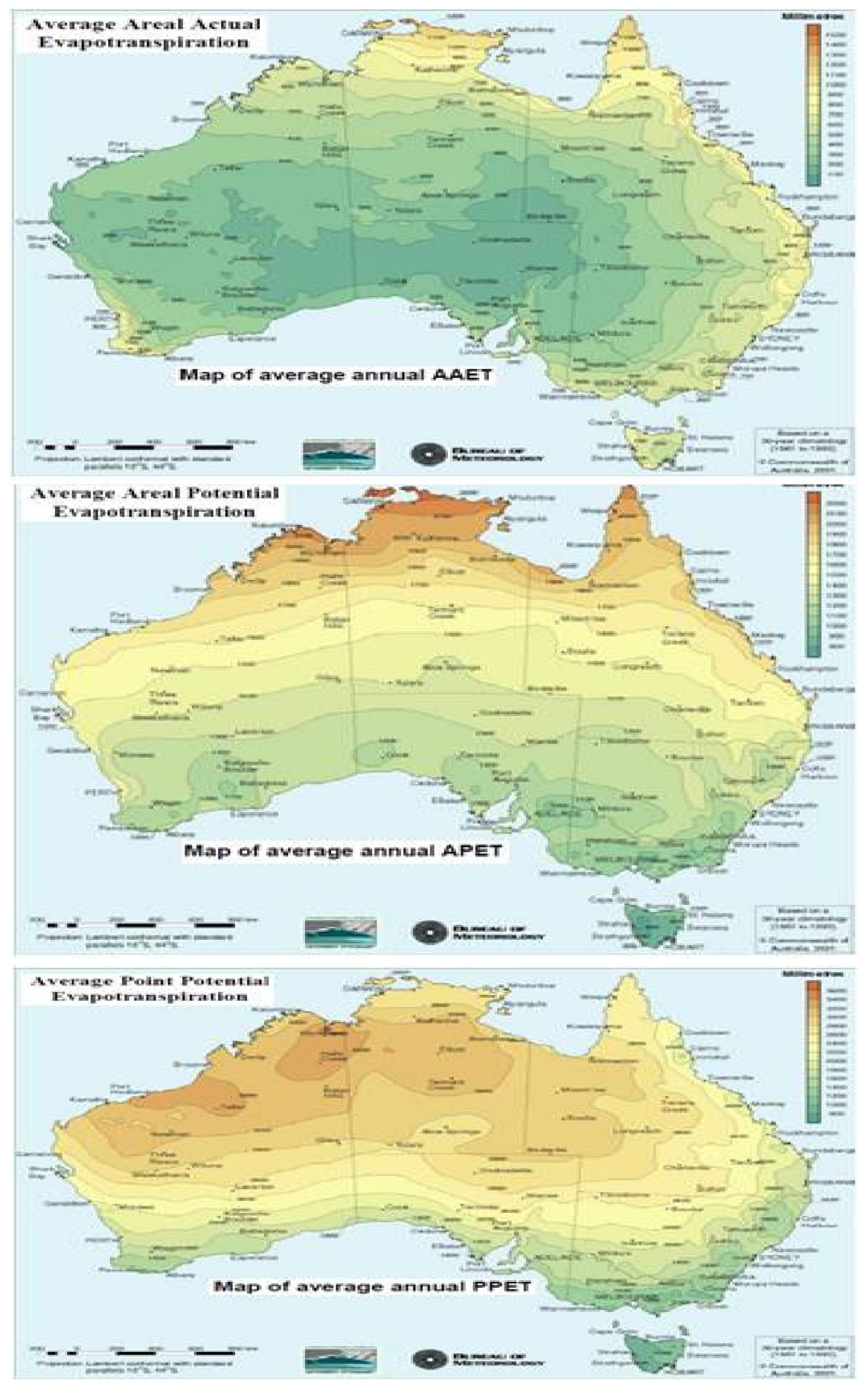


529

Rakesh Kumar et al. / J . A ppI. \& Nat. Sci. 5 (2): $522-534$ (2013)

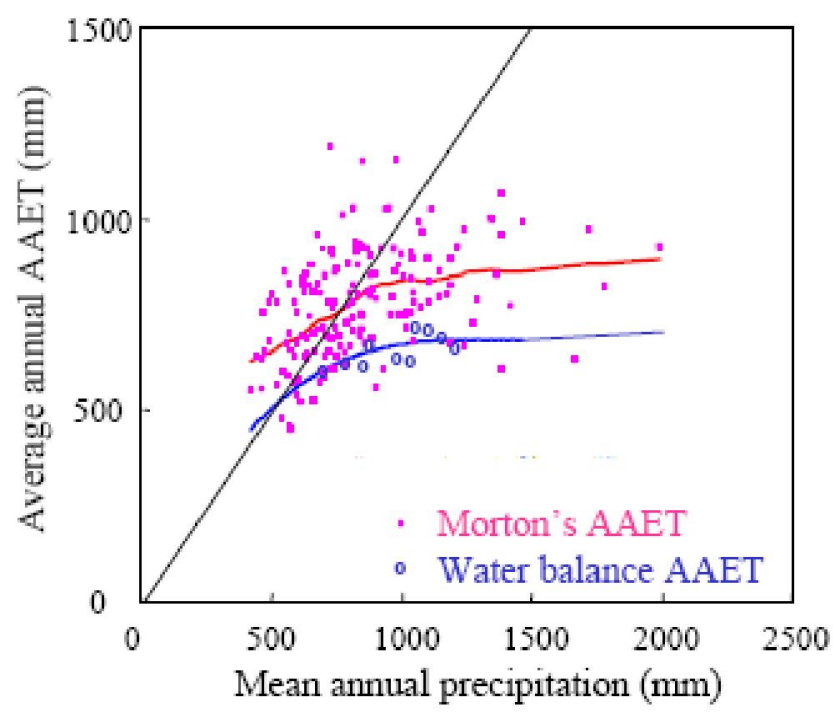

Fig.10. Method used to adjust M orlon's average annual AAET to match the water balance AAET (Source: Chew et al., 2002) result relatively similar to each other. At the same time, these are relatively similar to the results of water balance method (difference about $\Delta \mathrm{ET}_{\mathrm{R}}= \pm 5-10 \%$ ). The monthly distribution of the real evapotranspiration values according to the Thornthwait method haven been graphically represented in Fig. 7.

Deficit evaporation $\mathrm{E}$ is computed as the difference $(\Delta \mathrm{E}$ $=\mathrm{ETo}-\mathrm{ET}_{\mathrm{R}}$ ). $\mathrm{E}$ in Albanian varies about $\mathrm{E}=425$ to $450 \mathrm{~mm}$ on the coastal area to $\Delta \mathrm{E}=150$ to $200 \mathrm{~mm}$ in the mountains. The annual distribution of pluviometric deficit " $\mathrm{E}$ in Albania has been represented in Fig. 8, wherein it is evident that during the June-September period DTp is greater than the rainfalls, consequently there is shortage of water-supply. The opposite happens during the October-May period when the rainfalls are greater than

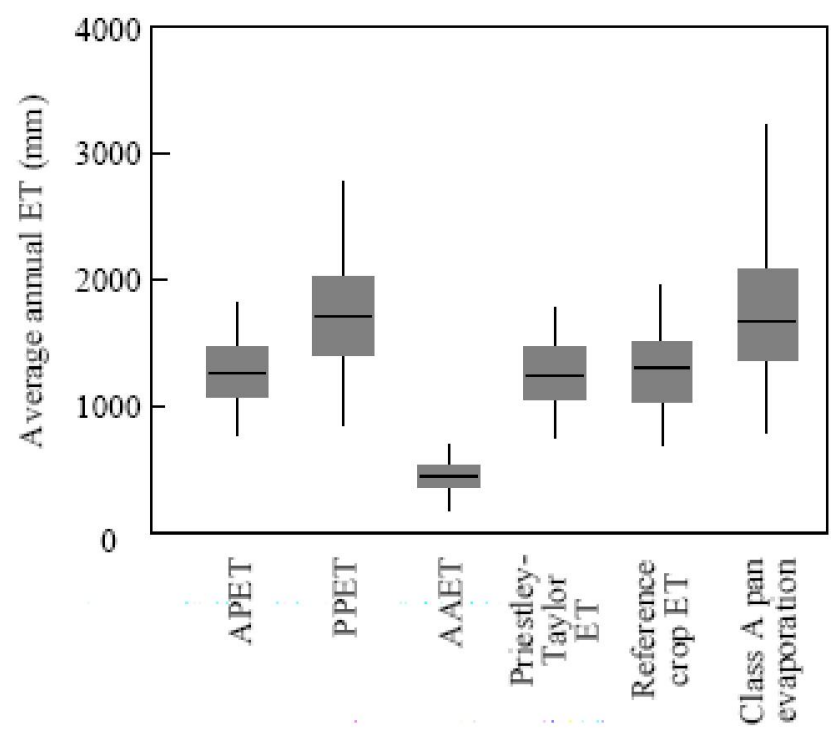

Fig.11. Spread of average annual values of various ET variables (Source: Chew et al., 2002).

evapotranspiration, consequently there are excessive rainfalls.

Evapotranspiration maps for Australia (Fig. 16)

Over the continent of Australia, ET is more than $90 \%$ of precipitation. Chew et al. (2002) mapped evapotranspiration variables: Areal actual evapotranspiration (AAET), Areal potential evapotranspiration (APET) and Point potential evapotranspiration (PPET). Mean monthly solar global exposure data derived by satellite radiance observations are used for the ET computations because solar global exposure is very sparsely observed in Australia. Morton's (1983) complementary relationship AAET model is used to estimate the ET variables.

$\mathrm{AAET}+\mathrm{PPET}=2 \mathrm{APET}$

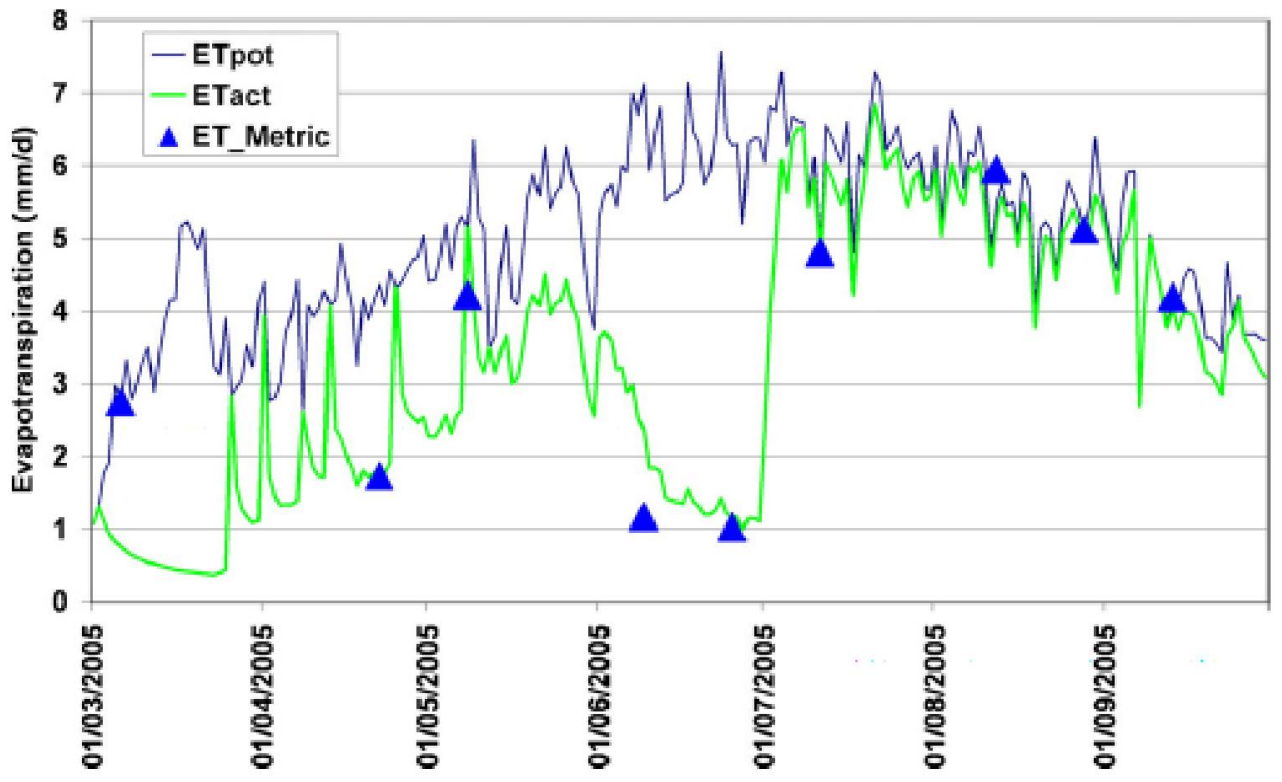

Fig.12. Comparison between simulated actual evapotranspiration (EPact) and satellite derived eva potranspiration (ET Metric) (Source: D roogers et al., 2010). 

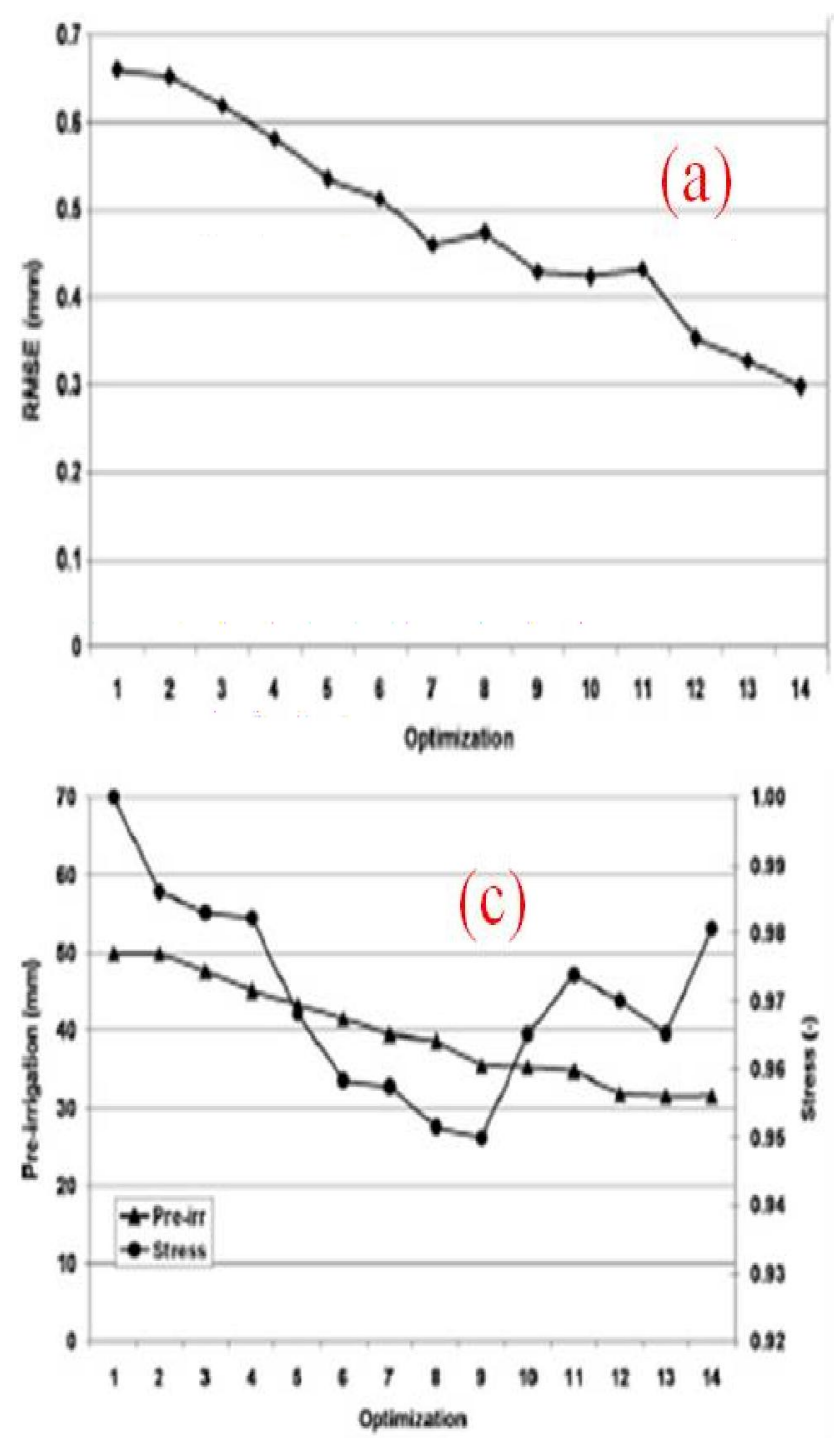

Fig.13. Typical example of optimization results: reduction in RMSE (a), changes in parameters (b) and performance of optimization (c) (Source: D roogers et al., 2010).

The complementary relationship considers that changes in the availability of water for AAET

respond in a complementary way to changes in the PPET (Morton, 1983). It states that under normal conditions, the sum of AAET and PPET is equal to twice the APET (Fig.9).

Under dry conditions, there is no water to evaporate and $\mathrm{AAET}=0$ and PPET is at its maximum rate. As water becomes available, AAET increases. This increase in AAET causes the over passing air to become cooler and more humid (reducing the vapour pressure deficit at a point), producing an equivalent decrease in the PPET. Finally, when the soil water has increased sufficiently, the values of AAET and PPET converge to that of the APET. The APET therefore depends only on the meteorological conditions, while the AAET and PPET also depend on the soil water availability in the surrounding area.

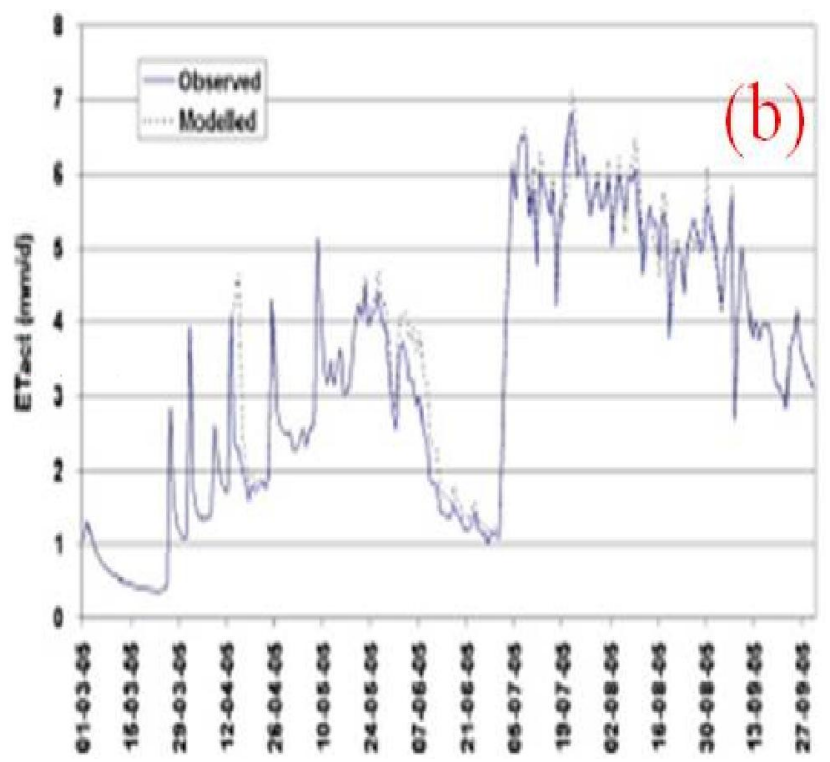

In Morton's model, the PPET is estimated by energy and vapour transfer equations

$\mathrm{PPET}=\mathrm{R}_{\mathrm{T}}-\lambda_{\mathrm{T}}(\mathrm{Tp}-\mathrm{T})$

$\mathrm{PPET}=\mathrm{f}_{\mathrm{T}}($ es - ea $)$

Where $R_{T}$ - net radiation at air temperature, $T$ - air temperature, $\mathrm{Tp}$ - equilibrium temperature, es - saturation vapour pressure at air temperature, ea - actual vapour pressure, $\lambda$ - heat transfer coefficient and $\mathrm{f}_{\mathrm{T}}$ - vapour transfer coefficient.

APET is estimated by modified Priestley-Taylor equation APET $=1.26(1+\gamma \mathrm{p} / \Delta \mathrm{p})-1 \mathrm{R}_{\mathrm{T}}$

Where $Y$ - psychrometric constant, $\mathrm{p}$ - atmospheric pressure, $\Delta \mathrm{p}$ - slope of saturation vapour pressure on temperature curve at equilibrium temperature and $R_{T}$ net radiation at equilibrium temperature.

Morton's model appears to underestimate winter ET and overestimate summer ET. To obtain more realistic ET estimates for the maps, the three average monthly ET variables estimated using Morton's model are adjusted. Morton's average annual AAET estimates are then adjusted by the difference between the two lines in Fig. 10. The method therefore adjusts the mean of Morton's AAET series at a given rainfall to the mean of the water balance AAET series at the same rainfall, whilst preserving the variance.

Following the above adjustment, there are still some locations where the average annual AAET exceeds the average annual rainfall or appears to be too low. Where this occurs, the average annual AAET is set to an arbitrarily defined lower or upper limit. One of three methods is used to adjust Morton's estimate of average monthly AAET depending on the average annual rainfall. Where the average annual rainfall is greater than 600 $\mathrm{mm}$, the monthly AAET is scaled upwards or downwards by the adjustment applied to the annual AAET. Where the average annual rainfall is less than $400 \mathrm{~mm}$, the 

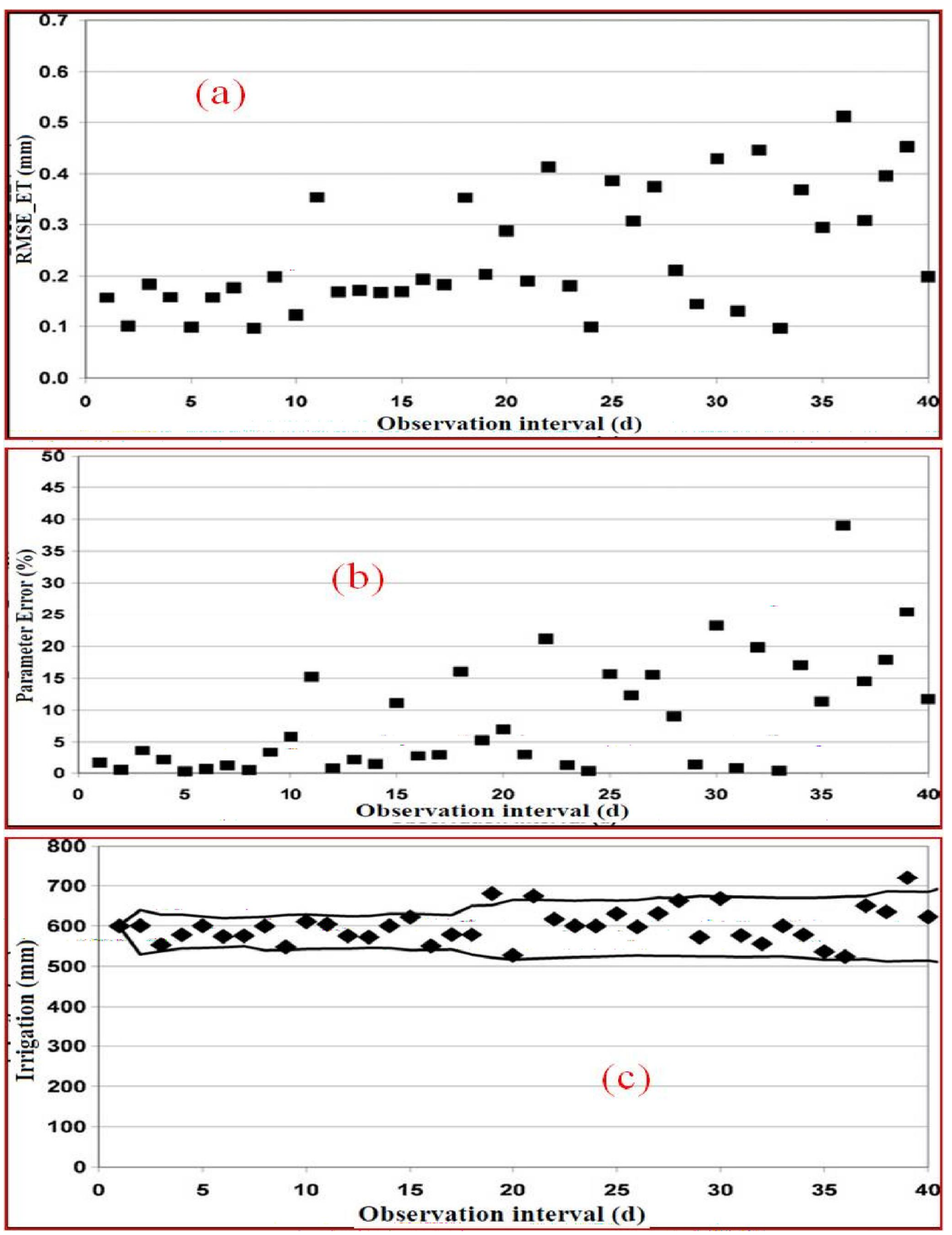

Fig.14. (a) RM SE as a function of the observation interval, (b) Parameter error as a function of the observation interval and (c) Irrigation application as a function of observation interval. Lines indicate two times standard deviation based on a moving interval of 5 days (Source: Droogers et al., 2010). 


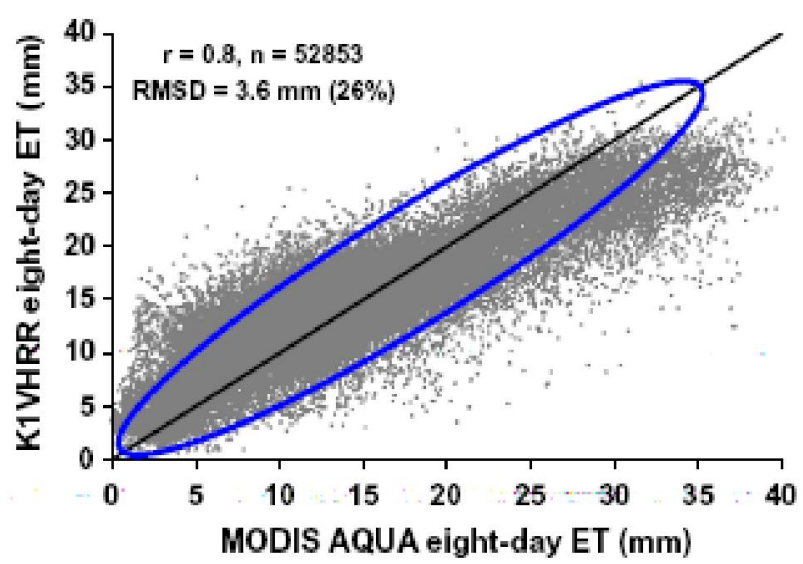

Fig.15. Comparison of K IVH RR clear sky eight-day ET (0.08) with MODIS AQUA ET over agro-ecosystems during Rabi growing season in Indian subcontinent (Source: Bhattacharya et al., 2010).

monthly AAET is set to equal the monthly rainfall. Where the average annual rainfall is between 400 and $600 \mathrm{~mm}$, a weighted average (as a linear function of rainfall) of the above two methods is used. The average monthly and annual ET variables interpolated to produce gridded data. The elevation, latitude and longitude are used as the explanatory variables. The gridded data are then imported into the Arc/Info GIS engine and mapped using the map creation tools within the GIS software suite.

The average annual PPET values at the 60 stations are similar to the average annual class (Fig. 11). A pan evaporation (for high ET values, PPET is slightly lower than pan evaporation). The average annual APET values are similar to the average annual Priestley-Taylor ET and reference crop ET values. It provides suggestions on where they can be used.

Estimating actual irrigation application by remotely sensed evapotranspiration observations: To assess irrigation application amounts, Droogers et al. (2010) used actual ET observed by satellites in southern Spain. It is based on three main tools applied to one irrigated field SEBAL (Surface Energy Balance Algorithms for Land) was applied to assess the actual ET based on Landsat remote sensing images. SWAP (soil-water-atmosphereplant) estimate daily actual ET based on prevailing conditions of particular field. Using PEST (Parameter estimation) program, SWAP input were adjusted to obtain the same actual ET as observed from the satellite. The derived input for SWAP can be considered as a representation of the real irrigation applications.

Output of a SWAP run are plotted in Fig. 12, based on realistic estimates of four times a pre-irrigation value of $25 \mathrm{~mm}$, and 0.95 for the stress threshold value. Clearly three crop stages can be observed during the growing season. At the beginning of the growing season the actual evapotranspiration is substantially lower than potential evapotranspiration as the crop is not yet fully developed. The figure indicates that the model simulated the observed satellite actual evapotranspiration well, based on the assumed pre-irrigation and stress threshold value. Optimization was performed algorithm as explained before. Two parameters (pre-irrigation and daily stress irrigation threshold values) were optimized by using the PEST program. A total of 15 optimization steps were taken, requiring 84 model calls. After these 15 optimization steps the process terminated because relative parameter changes were less than 0.01 and no further improvement could be expected. A steady reduction in RMSE during the first seven optimization steps, followed by a somewhat more irregular pattern in RMSE improvement is shown in Fig. 13 (a). The two parameters being optimized: pre-irrigation amount and stress threshold value reflect a similar pattern. During the initial phase of optimization the parameters follow a more or less linear pattern towards the optimum value.

The two parameters being optimized: pre-irrigation amount and stress threshold value, reflect a similar pattern. During the initial phase of optimization the parameters follow a more or less linear pattern towards the optimum value. The overall objective of this research is to see whether actual irrigation applications can be observed using a combination of actual evapotranspiration and model optimization. Observation intervals of actual evapotranspiration between 1 and 40 days have been used in the optimization process. It is indicated from the Fig. 13 that there is a clear trend in the RMSE (between actual evapotranspiration observed and the actual evapotranspiration simulated) with increasing observation intervals. As long as observation intervals are more frequent than 15 days, the RMSE is constant at a value of around $0.15 \mathrm{~mm}$ (is less than $4 \%$ error). At intervals longer than 15 days RMSE increases and the model is less accurate in simulations of observed actual evapotranspiration.

It is clear from Fig. 14 that the parameter error is relatively low provided the observation interval is within 15 days (with the exception of day 11). Beyond this, parameters cannot be accurately optimized. Similar as to the RMSE, the parameter error is relatively small for some interval days. However, given the overall variation, these small parameter errors are probably coincidental. The real irrigation obtained using the forward SWAP simulation was $600 \mathrm{~mm}$. The results from Fig. 14(c) indicates that independently to the observation interval, all obtained irrigation applications, with the exception of one, are within $500-700 \mathrm{~mm}$. There is however a clear trend which indicates that if the observation interval is shorter than 15 days, irrigation applications can be assessed at an accuracy of about $95 \%$. If observations are less frequent than these 15 days accuracy decreases to about $85 \%$. 
R egional clear sky evapotranspiration over agricultural land using remotesensing data from I ndian geostationary meteorological satellite: A simplified single-source energy balance scheme was implemented by Bhattacharya et al. (2010) to estimate regional clear sky ET using noon midnight data acquired from Indian geostationary meteorological satellite (Kalapana-1) sensor (VHRR) (hereafter termed K1VHRR). The 1:1 regional scale validation plot of K1 VHRR ET with aggregated MODIS AQUA clear sky 8-day ET for Indian agricultural land uses is shown in Fig. 15.

The data points falling inside the blue marked area represent inherent homogeneous agricultural patches. But data points falling outside this area correspond to those agricultural patches having varying level of crop distributions producing heterogeneity. This was determined by plotting the 2D scatters between K1VHRR and MODIS AQUA ET over 15 agro-climatic regions separately. It is known that the agricultural land uses are intensive and relatively homogeneous over Indogangetic belt extending from Trans Gangetic Plains Region (TGPR) to Lower Gangetic Plains Region (LGPR) through Upper Gangetic Plains Region (UGPR) and Middle Gangetic Plains Region (MGPR). The heterogeneous and ill-posed agro-ecosystems are dominant over Western Dry Region (WDR), Gujarat Plains and Hills Region (GPHR), Central Plateau and Hills Region (CPHR) and Southern Plateau and Hills Region (SPHR). The overall correlation of the validation plot was 0.8 (RMSD 26\% of MODIS AQUA mean) from 52,853 paired datasets. It is evident from this analysis that the overall errors have been reduced in 8-day ET due to possible elimination of spurious values in the basic datasets while compositing.

L imitations and future challenges:

Radiometric versus aerodynamic temperature: Radiometric temperature is sensitive to canopy structure, vertical vegetation temperature distribution, and row spacing and soil-vegetation component temperatures, regardless of the type of platform used (i.e., ground, airborne, or satellite) or sensor characteristics (i.e., band pass response, field of view, internal calibration). When two targets (e.g., soil and vegetation) at different temperature levels are viewed by the sensor, equality of radiometric and aerodynamic temperature should not be expected (Norman et al., 1995).

Spatial and temporal resolution: There is usually a tradeoff between spatial (i.e., pixel size) and temporal (i.e., repeat frequency) resolution for satellite platforms. e.g. Landsat 5 has a repeat cycle of 16 days with $30-120 \mathrm{~m}$ spatial resolution compared with daily coverage of MODIS with 250- 1,000 m. The spatial resolutions of thermal bands are often coarser than other wavelengths such as visible, NIR and SWIR (Shortwave-Infrared). For example, MODIS provides thermal images at 1,000-m resolution compared with $250-\mathrm{m}$ resolution for images acquired in other bandwidths on the same satellite platform. The ET maps derived from remote sensing data acquired by satellite-based sensors with daily coverage are useful in agricultural regions. Limited research has been done to evaluate the scale influences on the estimation of ET using multiple aircraft and satellite sensors. One main drawback at present with microwave data is that the spatial resolutions of passive microwave sensors are on the order of 10-100 km limiting their use to global scale applications. With the advent of improved algorithms, we may be able to use active microwave sensors that provide data at high spatial resolutions.

Data accuracy: One main drawback of existing EB methods is that they rely on the presence of extreme Ts (hot and cold or dry and wet) pixels in the imagery. Without the presence of high water use crops in the imagery, these methods may under-scale the true potential surface temperature range, thus leading to errors in the spatial ET estimation. Other errors with the EB models may relate to the spatial validity of weather station data.

Data processing time and user friendliness: To reiterate, the usefulness of remote sensing in the estimation of irrigation water demand will depend on the turn around time between image acquisition and the dissemination of derived ET information. At present, the turn around time is anywhere from 1 to 3 weeks depending on the remote sensing platform/sensor, algorithm utilized, and technician's experience/expertise on applying such algorithms. However, for most agricultural applications, ET maps should be delivered within hours, and almost instantaneous (i.e., real-time) timeliness is required for irrigation scheduling. Research should include programs geared towards rapid processing and analysis of remotely sensed imagery with the aid of artificial intelligence, to make ET maps readily available to producers, researchers, and the public by publishing daily digital ET maps over the Internet.

M odel validation: Most studies used BR and/or EC data for development and calibration of regional scale EB models. Measurements of latent heat flux differed by up to $29 \%$ between BR and large, weighing lysimeters for irrigated alfalfa during advective conditions in the Southern High Plains of Texas (Todd et al. 2000). Therefore, calibration of the EB models against lysimetric measurements over irrigated and dryland conditions may enhance their ability to estimate regional ET accurately.

\section{Conclusions}

Reliable regional ET estimates are essential to improve spatial crop water management. Automated Contours are not confined to specific predetermined geographic areas 
(as in MLRA), require less time and cost. ET estimation errors associated with EB models were $2.7-35 \%$ for daily ET and less than $6 \%$ for seasonal ET. Reflectance based crop coefficient methods are relatively easy to use to estimate ET compared to EB models, however, crop coefficients require calibration for each crop type. There are opportunities to further improve these models through (1) developing methods for accurately estimating canopy temperature profiles, (2) testing spatial validity of the meteorological data. Research opportunities exist to improve the spatial and temporal resolution of ET by developing algorithms.

\section{REFERENCES}

Bhattacharya, B.K., Mallick, K., Patel, N.K. and Parihar, J.S. (2010). Regional clear sky evapotranspiration over agricultural land using remote sensing data from Indian geostationary meteorological satellite. J ournal of $\mathrm{H}$ ydrology, 387: 65-80.

Brochet, P. and Gerbier, N. (1972). Une methode pratique de calcul de l'hapotranspiration potentielle. Annales Agronomiques, 23(1), 31-49.

Cha'vez J.L. and Neale, C.M.U. (2003). Validating airborne multispectral remotely sensed heat fluxes with ground energy balance tower and heat flux source area (footprint) functions. ASAE Paper No. 033128. St. Joseph, Michigan.

Chiew, F., Wang, Q.J., McConachy, F., James, R., Wright, W. and deHoed, G. (2002). Evapotranspiration maps for Australia. Hydrology and Water Resources Symposium, Melbourne, 20-23 May, Institution of Engineers, Australia.
Church, M.R., Bishop, G.D. and Cassell, D.L. (1995). Maps of regional evapotranspiration and runoff/precipitation ratios in the northeast United States. J ournal of H ydrology 168: 283-298.

Droogers, P., Immerzeela, W.W. and Lorite, I.J. (2010). Estimating actual irrigation application by remotely sensed evapotranspiration observations. Agricultural Water M anagement, 97: 1351-1359.

Merkoci, A. L., Gjata, G., Bogdani, M. N., Dvorani, M. and Shkurti, E. (2010). An approach to mapping evapotranspiration by meteorological element with application to the territory of Albania. International Conference SDI - Skopje.

Morton, F.I. (1983). Operational estimates of areal evapotranspiration and their significance to the science and practice of hydrology, J ournal of $\mathrm{H}$ ydrology, 66: 1-76.

Najjar, G., Arnbroise, B. and Mercier, J.L. (1981). Measurement and mapping of potential evapotranspiration in a small mountainous watershed. Nordic H ydrology, 195206.

Norman, J.M., Kustas, W.P and Humes, K.S. (1995). A twosource approach for estimating soil and vegetation energy fluxes from observations of directional radiometric surface temperature. A gricultural Forest M eteorology, 77: 263-293.

Rouse, J.W., Haas, R.H. Jr., Schell, J.A. and Deering, D.W. (1974). Monitoring vegetation systems in the Great Plains with ERTS. In: Proceedings of the ERTS-1 3rd Symposium, vol 1. NASA SP-351. NASA, Washington, pp 309-317.

Todd, R.W., Evett, S.R and Howell, T.A. (2000). The Bowen ratio-energy balance method for estimating latent heat flux of irrigated alfalfa evaluated in a semi-arid, advective environment. Agricultural F orest M eteorology, 103:335-348. 